\title{
Patrones de crecimiento urbano en la Patagonia chilena: el caso de la ciudad de Coyhaique ${ }^{1}$
}

\author{
Gerardo Azócar García², Mauricio Aguayo Arias², \\ Cristian Henríquez Ruiz ${ }^{3}$, Claudia Vega Montero ${ }^{2}$ y \\ Rodrigo Sanhueza Contreras ${ }^{4}$
}

\begin{abstract}
RESUMEN
Las políticas de Estado junto con la importante oferta/demanda de productos inmobiliarios para población de mayor ingreso han orientado el desarrollo reciente de varias ciudades chilenas, originando nuevas formas urbanas. Si bien estos procesos han sido descritos y analizados para varias ciudades y áreas metropolitanas de Chile central, no existen suficientes antecedentes empíricos que den cuenta de la realidad del desarrollo urbano de las ciudades más australes del país, como el caso de Coyhaique en la Patagonia chilena. Este trabajo pretende identificar y analizar los patrones de urbanización de esta ciudad, en un contexto territorial caracterizado, entre otros aspectos, por la fragmentación geográfica, el aislamiento, dispersión de los centros poblados y concentración de la población en la capital regional. Se analiza la evolución y factores explicativos que dan cuenta de su rápido proceso de urbanización y, sobre la base de documentos técnicos, históricos y geográficos, se presentan estimaciones futuras del crecimiento de la ciudad.
\end{abstract}

Palabras clave: Ciudades australes, crecimiento urbano, factor sociodemográfico.

\begin{abstract}
State policies and real estate market destined to people with more economic power, have orientated the recent development of many Chilean cities, reinforcing old urban patterns and creating new ones. Even though these processes have been described and analyzed for many cities and metropolitan areas of Central Chile, there hasn't been enough evidence about the urban development in Southern Chilean cities; such is the case of Coyhaique, located in Chilean Patagonia. From this perspective this work aims to identify and analyze the urban growth patterns in the city, in a territorial context characterized, besides other aspects, for geographical fragmentation, isolation, dispersion of towns and concentration of population, services and facilities inside the regional capital. The urban growth pattern was analyzed using historical reviews about the evolution since the foundation in 1929. The methods used were GIS and photo interpretation of satellite images of different periods. Finally, urban growth estimation was made based on technical studies.
\end{abstract}

Key words: Southern cities, urban growth, socio-demographic factor.

1 Proyecto FONDECYT Nº 1070511 y Proyecto Dirección de Investigación, Universidad de Concepción DIUC N ${ }^{\circ} 205.310 .045-1$ sp. Artículo recibido el 15 de septiembre de 2009 y aceptado el 16 de noviembre de 2009.

2 Centro EULA-Chile, Universidad de Concepción
(Chile).E-mail: gazocar@udec.cl; maaguayo@udec. cl; clvega@udec.cl

3 Instituto de Geografía, Pontificia Universidad Católica de Chile (Chile). E-mail: cghenriq@uc.cl

4 Departamento de Geografía, Universidad de Concepción (Chile). E-mail: rsanhue@udec.cl 
El desarrollo urbano de Coyhaique debe ser entendido y analizado en el marco de los continuos esfuerzos de colonización realizados por el Estado de Chile, en una región austral territorialmente fragmentada y aislada. Las dificultades de conectividad $y$ accesibilidad fueron temas prioritarios durante gran parte del siglo XX, especialmente el de las comunicaciones internas. A través de la apertura de nuevas rutas o sendas de penetración, de la inversión del Estado y privada para consolidar y fomentar el poblamiento y surgimiento de enclaves productivos, la región de Aysén, y en particular los centros urbanos de Coyhaique y Aysén, han experimentado un rápido proceso de crecimiento urbano expresado, este último, en la creciente movilidad y desplazamiento de la población hacia la capital regional. Desde esta perspectiva, el sistema de centros poblados de la región presenta un marcado desequilibrio, tanto en cuanto a la concentración de actividades y población, conectividad y equipamientos, localización de mercados de trabajo y empleo, como a las oportunidades de desarrollo de los centros menores, especialmente costeros, frente al rol jerárquico y funcional que, lenta y sostenidamente, han ido adquiriendo a través de los años las ciudades de Coyhaique, Aysén y Puerto Chacabuco.

No obstante lo anterior, cabe destacar el esfuerzo histórico de varios gobiernos por favorecer la colonización y, junto a ello, mantener los flujos migratorios hacia la región, incentivando directa o indirectamente el desarrollo de actividades productivas y centros poblados. Lo anterior, principalmente, en territorios continentales localizados en torno a la carretera Austral, fiordos y otras áreas cercanas a Coyhaique y Balmaceda. En la actualidad, los flujos migratorios han tendido a decrecer y solo se agudizaron durante la década de los ochenta como resultado de la creación de un mercado para la comercialización de la merluza, lo que significó una inmigración masiva hacia la zona del litoral norte de la región, generando una fuerte presión sobre la dotación de servicios básicos en pequeños centros poblados continentales e insulares. A este fenómeno corresponde la generación de nuevos asentamientos humanos como los generados en el grupo de islas Gala (SERPLAC, 2005).
Históricamente, en la región de Aysén las condiciones geográficas han constituido un obstáculo permanente para el poblamiento y el desarrollo territorial. Vastas áreas del litoral, y del sector sur, aún se presentan prácticamente despobladas, y solo la franja oriental $\mathrm{o}$ andina ha sido un territorio preferente para el poblamiento y desarrollo de centros poblados. Ello como resultado de la instalación temprana de industrias de procesamiento de productos pecuarios, situación que favoreció la consolidación y el crecimiento urbano de las ciudades de Coyhaique y Puerto Aysén. En décadas más recientes, el proceso se ha visto reforzado con la apertura y mejoramiento de la infraestructura vial y conectividad asocia$\mathrm{da}$, con efectos positivos sobre las actividades acuícolas, mineras y turísticas, basadas en los atractivos naturales y culturales de la región.

Se entiende así que, tanto los factores de índole físico-geográfico, como el proceso de colonización, han favorecido, en buena medida, la concentración de la población regional en dos ciudades primadas, Coyhaique y Aysén, las cuales, actualmente, albergan al $77,8 \%$ de la población total regional y al $85 \%$ de la población total urbana. En otras palabras, se observa un continuo proceso de concentración urbana, especialmente a partir del año 2002 y, consecuentemente, una disminución del poblamiento en zonas rurales. La movilidad de la población es un aspecto característico del poblamiento regional y no estaría vinculada solamente, por lo menos en años recientes, con el antiguo proceso de colonización en la zona de los canales y en el área andina patagónica, sino más bien con la dinámica de la actividad pesquera, acuícola y turística. De este modo, los flujos migratorios no solo se producen desde las zonas o centros poblados rurales de menor jerarquía hacia las principales ciudades de la región, sino también, y como tendencia más reciente, hacia otros núcleos de poblamiento de rango intermedio, como es el caso de Puerto Chacabuco, Chile Chico y Melinka.

Desde un punto de vista demográfico la región no presenta un crecimiento vegetativo significativo de su población urbana, mostrando una tasa de crecimiento intercensal positiva de 19,6\%, entre los años 1992 y 2002, pasando de 57.194 a 69.134 habitantes y una variación porcentual negativa de su 
población rural de $-22,7 \%$. En otras palabras, la región muestra una tendencia general a la concentración de población en los centros urbanos, especialmente, en su capital Coyhaique. En la región de Aysén predominan, claramente, los componentes naturales del territorio y la ocupación humana se concentra en unos pocos asentamientos urbanos o bien en localidades aisladas (Romero et al., 2008).

La dinámica urbana de la ciudad de Coyhaique, capital regional y objeto de la presente investigación, se puede observar en su tasa de crecimiento anual de población. Entre los censos 1992 y 2002 alcanzó un 2,35\%, calificado de media a alta, superior a la tasa de crecimiento de la comuna $(2,08 \%$ anual) y, aún más, de la población regional $(1,28 \%$ anual). Es decir, es la ciudad, más que la comuna o la región, la que recibe los impulsos del crecimiento demográfico. Esta concentración progresiva de población en la ciudad sería explicada por la movilidad o migración de población desde zonas o centros urbanos y rurales de menor rango o jerarquía, de la comuna, de la región y de otras regiones del país, hacia la ciudad de Coyhaique.

Dicho proceso se ve reflejado en la oferta inmobiliaria y superficie edificada aprobada de la región: Coyhaique y Aysén, de acuerdo a datos del Censo del año 2002 (INE, 2002), concentran el $83,4 \%$ de las viviendas y el $90 \%$ de la superficie edificada a nivel regional. Más específicamente, y a partir de información disponible desde el año 1996, se construyeron en la región 1.046 viviendas subsidiadas con un total de $35.433 \mathrm{~m}^{2}$, de las cuales 739 se localizan en la ciudad de Coyhaique (70\%) (SEREMI MINVU, 2006).

Indudablemente, esta concentración y movilidad de la población ha provocado importantes transformaciones urbanas en Coyhaique, siendo uno de sus principales resultados el crecimiento en extensión de la ciudad en áreas o sectores preferenciales de desarrollo, particularmente a partir de la década de los noventa. $\mathrm{Al}$ respecto se puede observar que entre 1992 y 2008 la superficie total edificada tuvo una variación del $24,71 \%$. Diferentes formas o tipologías de crecimiento pueden ser observadas, actualmente, en la ciudad, claramente delimitadas y estructuradas a partir de su asentamiento fundacional y de elementos naturales que condicionan, limitan o bien potencian sus posibilidades de desarrollo urbano. En este sentido, destacan los ríos Simpson y Coyhaique, como también el cerro Divisadero.

Este auge urbano, austral y patagónico, no ha estado exento de algunos rasgos o características más generales del crecimiento de muchas ciudades chilenas en las últimas décadas, como son: su rol jerárquico y primado en la estructura de centros poblados de la región; una urbanización más bien reciente, acelerada por la incorporación de inversiones productivas de extracción de recursos naturales en los territorios de influencia de las ciudades y promovida por el mercado inmobiliario y políticas públicas en materia de construcción de viviendas por segmentos socioeconómicos.

Este auge urbano, austral y patagónico, no ha estado exento de algunos rasgos o características más generales del crecimiento de muchas ciudades chilenas en las últimas décadas, como son: su rol jerárquico y primado en la estructura de centros poblados de la región; una urbanización más bien reciente, acelerada y promovida por la incorporación de inversiones productivas de extracción de recursos naturales en los territorios de influencia de las ciudades, el mercado inmobiliario y políticas públicas en materia de construcción de viviendas sociales; y la segregación socioespacial originada o favorecida por la particular localización de la ciudad, en un entorno geográfico marcado por la presencia de importantes elementos o hitos naturales como ríos y montañas, y la condición social y origen de sus habitantes.

Los procesos antes mencionados y sus consecuencias urbanas, sociales y ambientales han sido analizados en grandes ciudades y ciudades intermedias de América Latina y Chile (Rodríguez y Villa, 1998; Hidalgo et al., 2003; Romero et al., 2005; Sabatini, 2000; Segura, 2003); específicamente, en ciudades intermedias de Chile central (Azócar et al., 2007; Henríquez et al., 2006; Azócar et al, 2003), identificándose una clara relación entre el crecimiento de ciudades con intensificación de los procesos económicos de despliegue de inversiones en las regiones y 
procesos sociales de diferenciación según segmentos de población, exclusión y segregación urbanas, especialmente para los usos residenciales e industriales (Sabatini, 1998; Romero y Toledo, 1998; Borsdorf, 2000; Rovira, 2000; Azócar et al., 2008).

Del mismo modo, importantes esfuerzos han sido realizados para identificar y comprender, más formal y científicamente, los factores que han orientado los cambios más recientes de las ciudades chilenas, los patrones de uso del suelo resultantes y sus efectos sociales y ambientales (Henríquez et al., 2006; Aguayo et al., 2007). De relevancia en dichas aproximaciones metodológicas ha sido el uso de herramientas Sistemas de Información Geográfica (SIG) y de técnicas de modelación de cambio de uso del suelo (Azócar et al., 2007; Aguayo et al., 2007; Henríquez et al., 2006).

No obstante ello, falta avanzar en el estudio de ciudades intermedias menores, preguntándose en qué medida es comparativo su comportamiento con ciudades intermedias y grandes, y cuánto les afecta el despliegue de inversiones en sus territorios. Para el caso de la zona austral de Chile, las ciudades han sido investigadas más bien desde una perspectiva histórica, con interesantes trabajos elaborados por cronistas e historiadores (Santelices, 2002; Pomar, 1923; Martinic, 2005). Más recientemente, análisis de cambios de uso del suelo y del paisaje, a nivel de cuencas hidrográficas, han sido realizados, especialmente en la cuenca del río Simpson (Vera, 2008). Sin embargo, no existen investigaciones específicas que den cuenta del comportamiento urbano más reciente de las principales ciudades de la región de Aysén que, al margen de la identificación de aquellos factores más generales que orientan los cambios o procesos de rápido crecimiento en ciudades de rango o jerarquías similares de Chile, evalúen con mayor detalle las formas, patrones de uso del suelo, tipologías de crecimiento y factores específicos que guían dichas transformaciones urbanas. De este modo, este trabajo, de carácter exploratorio, tiene como objetivo principal analizar los patrones de urbanización y uso del suelo en la ciudad de Coyhaique a partir de la década del ochenta, identificando los factores que han orientado o inducido el proceso de creci- miento urbano, como también sus diferentes tipologías o formas resultantes.

\section{Patrones de crecimiento urbano de ciudades chilenas y latinoamericanas}

Desde un punto de vista conceptual un patrón espacial puede ser entendido como las regularidades espaciales que resultan de las relaciones entre elementos, situación que implica, por un lado, reconocer un conjunto de estructuras y de procesos que condicionan o bien definen el desarrollo de una ciudad $y$, por otra parte, considerar una estructura espacial como un arreglo u organización locacional interna de una distribución de un fenómeno en el espacio, en este caso las ciudades. A su vez, los procesos espaciales pueden ser considerados mecanismos que originan la distribución de tales estructuras, como por ejemplo el movimiento y la difusión (Abler et al., 1971). Para Santos (2000), el tiempo y el espacio son fundamentales para comprender los patrones espaciales del crecimiento urbano, ya que cada período histórico genera estructuras espaciales representadas por técnicas y objetos característicos de ese tiempo y formas de acción. Discusiones y aplicaciones de este enfoque son muy numerosas, especialmente en los estudios provenientes de la literatura geográfica brasileña, donde los factores asociados a la globalización son de gran importancia en la exégesis del crecimiento de varias ciudades medias (Beltrão, 2007; Bellet y Beltrão, 2009).

Actualmente, existe un consenso tácito en la literatura en cuanto a que los patrones espaciales de crecimiento urbano de grandes ciudades latinoamericanas y también de varias ciudades intermedias son bastante parecidos. En este sentido, Borsdorf (2003) distingue cuatro fases del modelo de ciudad latinoamericana: Ia ciudad colonial, la ciudad sectorial, la ciudad polarizada y la ciudad fragmentada. Cada uno de estos estadios constituye una respuesta a la forma y tipo de evolución socioeconómica que se ha presentado en su historia urbana, variando gradualmente de una ciudad pequeña, homogénea social y económicamente, a una ciudad cada vez más grande y diferenciada (Henríquez y Azócar, 2007). Respecto a la última fase 
de fragmentación, que incorpora las transformaciones asociadas a las desigualdades sociales producidas por la globalización, se puede simbolizar por la libre distribución, o por lo menos no suficientemente planificada, de zonas industriales, por la localización de centros comerciales en toda la ciudad, orientados a las autopistas intraurbanas y aeropuertos, y por la presencia de barrios cerrados en todo el perímetro urbano y en la periferia extramuros que protegen a los sectores sociales exclusivos de la inseguridad ciudadana. También, esta fase se caracteriza por la consolidación de barrios marginales antiguos y por una disminución de estos en el centro de la ciudad debido, principalmente, al proceso de gentrificación y al impacto de los programas de renovación urbana. Además, otra característica de esta etapa es que el crecimiento del espacio urbano ya no es guiado solo por la presión migratoria, sino por otras fuerzas conducentes ligadas, por ejemplo, a la condición socioeconómica de la población (Henríquez y Azócar, 2007). Esto último resulta de especial relevancia para ciudades patagónicas, donde la inmigración se ha constituido en un factor relevante en el desarrollo urbano de Coyhaique, como se verá más adelante.

En general, el clásico crecimiento tipo "mancha de aceite", controlado por un desplazamiento horizontal de la población y servicios urbanos hacia los bordes de las ciudades y por la acreción de suelos rurales a la trama urbana, ha estado guiado, generalmente, por las redes de comunicación y por la accesibilidad (Herbert y Thomas, 1982), procesos que han dado origen a nuevas formas y tipos de patrones espaciales, como el denominado crecimiento tipo "salto de rana". En este último caso, se trata de un desarrollo urbano discontinuo o bien no continuo, en el cual los enclaves urbanos ocupados por distintos segmentos sociales se emplazan en el medio periurbano (Clawson, 1962; Goodall, 1972). Por otra parte, las ciudades latinoamericanas también presentan patrones denominados tentaculares, que corresponden al crecimiento horizontal a partir de vías estructurantes o bien a la localización de actividades industriales en torno a nodos de transporte y comunicación, junto con un crecimiento por densificación en altura asociado a programas de renovación urbana en las áreas más centrales de la ciudad. En síntesis, se puede afirmar que la ciudad latinoamericana o por lo menos muchas de ellas presentan en su evolución urbana una combinación de patrones, cuyo común denominador es su carácter fragmentado, segregado y disperso.

¿Estos procesos se pueden encontrar en ciudades más pequeñas? Los cambios aludidos parecieran no solo afectar a las grandes ciudades chilenas, sino también a las ciudades intermedias capitales regionales, especialmente las que ostentan signos de metropolización y a pesar de las especificidades propias de cada una de ellas (Hidalgo y Arenas, 2009). No obstante, en la ciudad de Coyhaique, ciudad en el tránsito de pequeña a media o intermedia, algunos de estos fenómenos urbanos que parecen exclusivos de ciudades más grandes efectivamente estarían ocurriendo.

\section{Materiales y métodos}

El análisis de la evolución de la trama urbana de la ciudad de Coyhaique, como también el uso del suelo y localización de equipamientos, servicios e infraestructura, se realizó mediante interpretación de imágenes satelitales Ikonos-2 PAN/MSI del año 2006 e imágenes Landsat del año 1984. A partir del procesamiento de las imágenes se generaron una serie de coberturas en formato vectorial en el SIG ArcView 3.2, las que fueron posteriormente verificadas y validadas en terreno. De especial relevancia son las coberturas de áreas urbanas de los años 1984, 2006 y 2008, uso del suelo, infraestructura vial, ríos y localización de equipamientos, servicios e infraestructura. El análisis de la evolución histórica de la ciudad fue complementado con material bibliográfico y cartográfico, lo que permitió disponer de una cobertura urbana de Coyhaique para el año 1949 y décadas posteriores. La información demográfica, especialmente la tasa de crecimiento y variación intercensal de la población comunal y urbana, fue obtenida de los Censos de Población de los años 1992 y 2002 (INE, 1992; INE, 2002), representándose cartográficamente los cambios y/o tendencias entre ambos períodos. El procesamiento de los datos, a nivel de distrito censal, fue realizado con el software REDATAM G-4 (CELADE, 2001). 
La caracterización y análisis de los patrones de crecimiento urbano, observados entre los años 1984 y 2008, se realizó sobre la base de las diferentes tipologías de crecimiento identificadas y su distribución espacial en la ciudad y entorno circundante. Con el uso del módulo Spatial Analyst de ArcView 3.2 se calcularon las distancias medias de estas formas de crecimiento respecto a la infraestructura vial, equipamientos, servicios y al área urbana fundacional de la ciudad de Coyhaique. En este último caso, se calculó la distancia del área urbana observada el año 2008 respecto del casco de la ciudad del año 1949, incorporando en este análisis los proyectos de loteos y parcelaciones. Estimaciones de densidades de ocupación del suelo, para diferentes tipologías o formas de crecimiento residencial fueron calculadas, como también las respectivas densidades de población para dichos emprendimientos. Lo anterior, con el uso de imágenes satelitales Ikonos del año 2006 y verificación en terreno. Finalmente, y sobre la base de antecedentes bibliográficos, se presentan estimaciones de crecimiento futuro de la ciudad, basadas en la dinámica económica regional-comunal, en las proyecciones de crecimiento y movilidad de la población, en las demandas de viviendas y equipamiento asociado para diferentes grupos sociales y en lo establecido en los instrumentos de planificación urbana para la ciudad de Coyhaique.

\section{Área de estudio}

La comuna de Coyhaique se ubica en la zona central de la Región de Aysén del General Carlos Ibáñez del Campo y posee una superficie de $7.775 \mathrm{~km}^{2}$, cifra que representa el $7,1 \%$ de la superficie regional. La mayor parte de la comuna se emplaza en el piedmont oriental de la cordillera de los Andes, limitando con la República Argentina, hacia el este, y las comunas de Lago Verde, hacia el norte, Río Ibáñez, hacia el sur y Aysén, hacia el poniente. La población comunal alcanzó los 50.041 habitantes el año 2002 (INE, 2002), con una variación anual de un 2,08\% entre los Censos de 1992 y 2002.

La ciudad de Coyhaique, palabra que en idioma tehuelche está compuesta de koi, sinónimo de laguna, y aikén, paradero o campamento, se localiza en el piedmont de la cordillera de los Andes, en la confluencia de los ríos Coyhaique y Simpson (Figura $\mathrm{N}^{\circ}$ 1). Su trama urbana y el asentamiento de la población, además de los ríos antes mencionados, se ha estructurado por la presencia del cordón El Divisadero, hacia el sur, la Reserva Nacional Coyhaique, hacia el norte, y varios cursos de agua, de flujo intermitente, que drenan el cordón El Divisadero y que han condicionado la localización de la población sobre, principalmente, las terrazas de origen fluvial que dichos esteros y ríos han modelado.

La ciudad se divide en cuatro distritos censales que albergan una población de 44.987 habitantes (INE, 2002), cifra que representa el $49,2 \%$ de la población regional y el $89,9 \%$ de la población de la comuna de Coyhaique. Si bien entre los Censos de 1992 y 2002 la comuna de Coyhaique experimentó una baja sustantiva en su tasa de crecimiento poblacional, pasando de 2,2\% entre 1982 y 1992 a 1,2\% entre 1992 y el año 2002, la ciudad continúa creciendo y concentrando cada vez más no solo la población rural de su propia comuna, sino que también gran parte de los flujos migratorios provenientes de otras localidades de la región de Aysén y de otras regiones del país. Lo anterior ha acentuado cada vez más su rol primado y jerárquico, generando, en las últimas décadas, una fuerte presión sobre los límites urbanos establecidos en los instrumentos de planificación urbana, sobre los equipamientos, servicios e infraestructura vial, sanitaria y energética. De este modo, Coyhaique cumple una función eminentemente de servicios, públicos y privados, respecto a todo el territorio regional, concentrando, además, prestaciones comerciales, financieras y todas aquellas requeridas para el desarrollo de las actividades pesqueras, acuícolas, ganaderas, agrícolas, mineras y turísticas, básicas en el desarrollo económico y productivo de la región de Aysén.

Este proceso de acelerada urbanización y concentración de la población en la capital regional, se ha traducido en una creciente demanda por suelos urbanos de uso residencial y actividades asociadas, generando continuas modificaciones en los límites urbanos y la definición de nuevas áreas de expansión residencial para diferentes grupos socioeconómicos. En este contexto, Coyhaique, al 
igual que muchas otras ciudades de Chile, ha ido adquiriendo a través de los últimos años una fisonomía urbana marcadamente segregada, favorecida por elementos naturales que actúan como verdaderos separadores de actividades, usos del suelo y grupos sociales bastante diferenciados. La trama urbana de la ciudad ha crecido rápidamente en extensión y distancia, alejándose cada vez más del casco fundacional y dando origen a nuevos patrones o formas de urbanización.

Desde un punto de vista económico, la ciudad de Coyhaique se caracteriza por ser el principal centro de servicios profesionales, administrativos y financieros de la región de Aysén, concentrando en el sector de servicios más del $80 \%$ del empleo comunal. Tan solo un $12 \%$ corresponde a trabajo generado por actividades primarias, principalmente agropecuarias, y un $6 \%$ por el sector industrial. Es decir, la comuna y ciudad de Coyhaique están orientadas básicamente hacia las actividades terciarias, generadoras de buena parte del empleo comunal, provincial y regional. Indudablemente, este aspecto ha influido po- sitivamente en la movilidad de la población hacia la capital de la región de Aysén.

\section{Resultados}

\section{La etapa fundacional}

La favorable ubicación del casco de la estancia Coyhaique, en la confluencia de dos ricos valles ganaderos, en el acceso al Aysén oriental más poblado y productivo, fue una de las razones para que el año 1929 el coronel Marchant, intendente de la región de Aysén bajo el gobierno del presidente Ibáñez, fundara en aquellos parajes el poblado de Baquedano. Sin embargo, solo el 21 de mayo del año 1931 ocurriría la fundación definitiva del pueblo de Baquedano, el cual tomaría definitivamente el nombre de Coyhaique el año 1935. En esa época, el incipiente poblado contaba con solo unas treinta viviendas, eran los albores de una de las ciudades más australes del continente americano y se iniciaba la construcción de almacenes, tiendas y de los primeros edificios públicos, como

Figura $\mathrm{N}^{0} 1$

Área de estudio

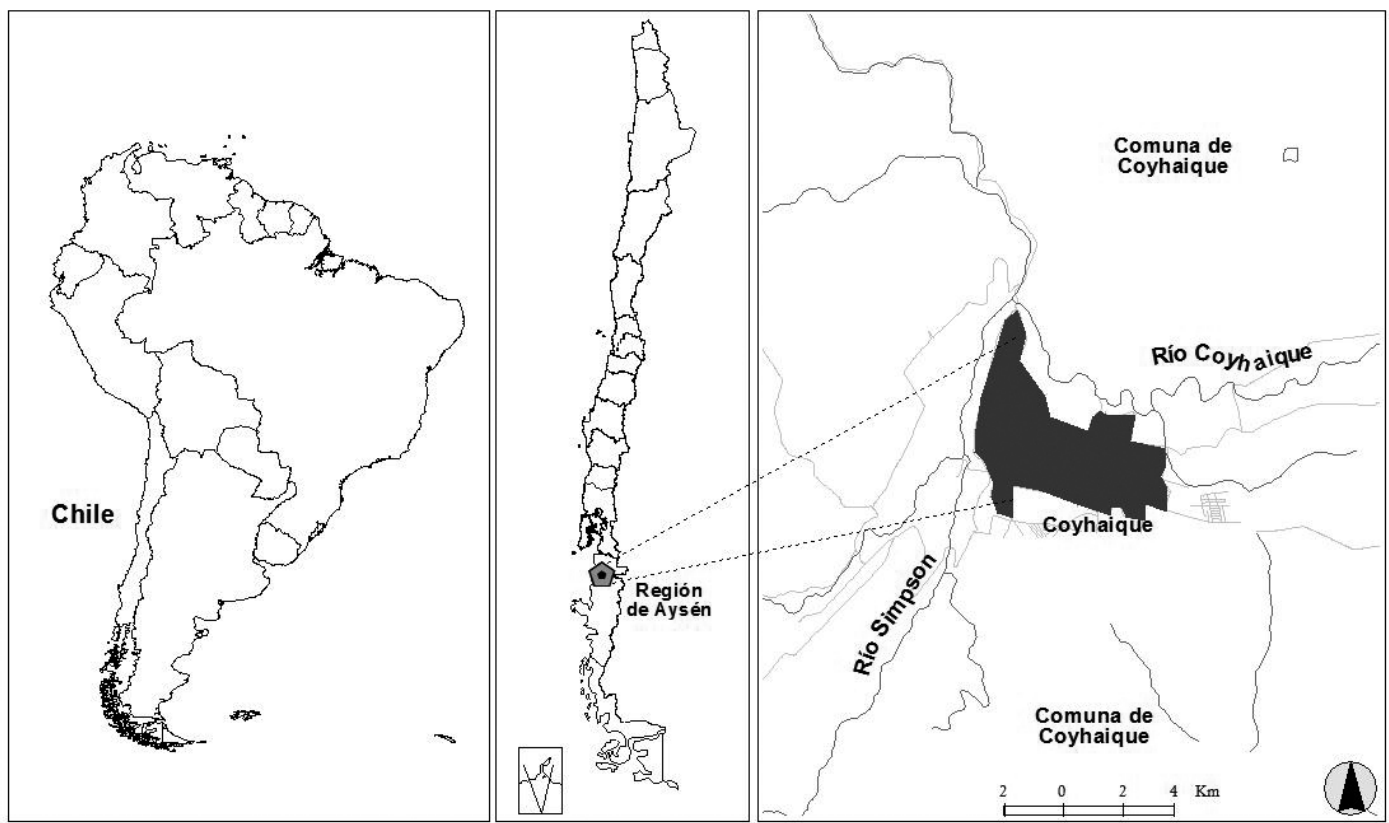

Fuente: Elaboración propia. 
el de la Subdelegación y el de la Oficina de Tierras (Santelices, 2002). Las apropiadas condiciones geográficas y de recursos naturales permitirían la fundación del poblado de Baquedano, como bien lo describe José Pomar el año 1923:

“...El valle de Coyhaique está dividido según su altura en dos partes: la más oriental Ilamada Coyhaique Alto y la más occidental Ilamada simplemente Coyhaique y por otros Coyhaique bajo... La primera es boscosa y adecuada para la crianza de vacunos y la segunda es compuesta de coironales abiertos y apropiados para la crianza de ovejas..." (Pomar, 1923: 37).

Las necesidades administrativas de crear un nuevo centro poblado, debido a las presiones de los pobladores del valle del río Simpson y al interés de los trabajadores de la estancia Coyhaique de radicarse y tener algo propio, fueron algunas de las razones del gobierno de la época para fundar la futura ciudad de Coyhaique (Santelices, 2002). Además de estos argumentos, la posición geográfica del sitio fundacional, entre los ríos Simpson y Coyhaique, y su posición como punto central o de convergencia de los caminos hacia Balmaceda, Río Ibáñez, Chile Chico y Baker, por la parte sur, y hacia Ñirihuao, Lago Verde y Río Grande, por el norte, determinarían la ubicación definitiva del centro poblado. En otras palabras, dicha localización respondía a una situación geográfica privilegiada desde el punto de vista de las comunicaciones y del transporte de personas, bienes y productos originados en la economía ganadera de la época, permitiendo, además, consolidar y promover el proceso colonizador y su integración con la Patagonia argentina.

El nuevo poblado sería fundado en el sector denominado La Pampa del Corral, con una extensión de 400 por 800 metros, en lo que actualmente corresponde a las calles Baquedano con Simpson y Colón con Parra, con una superficie original que alcanzaría, aproximadamente, a las 32 hectáreas (Santelices, 2002). Respecto al sitio fundacional, las descripciones de la época son elocuentes, tal cual lo señalará el ingeniero Jefe de Tierras de aquella época Sr. Fernando Sepúlveda Veloso: "...Se nos presentó la planicie del ac- tual pueblo como un hermoso conjunto de la junta de dos ríos, el Coyhaique y el Simpson, de los faldeos asoleados del cerro Coyhaique (Divisadero?...) y de la unión de dos caminos internacionales, teniendo a su espalda los picachos de la cordillera de Los Andes..." (Santelices, 2002: 874).

En dicho sitio, y desde sus orígenes, la plaza y sus alrededores tuvieron un rol de importancia en la vida de sus primeros habitantes: lugar de emplazamiento de las primeras viviendas y edificios públicos, área de recreación y esparcimiento para los colonos, lugar de juegos tradicionales y de carreras de caballo. Es así como el nacimiento del pequeño poblado estuvo vinculado a la existencia de una plaza, la que actuó, desde sus inicios, como elemento ordenador y estructurador del futuro desarrollo de la ciudad. Más tarde, el año 1929, el Ministerio de Tierras y Colonización realizaría las primeras mensuras de sitios, siendo el agrimensor Héctor Monreal encargado del diseño de la plaza de armas dentro de un pentágono, lo cual resultaría peculiar respecto a la forma tradicional de las plazas chilenas.

Históricamente, Coyhaique ha jugado un rol funcional y jerárquico en el territorio patagónico, tal cual lo expresará el reconocido poeta, dramaturgo, novelista y pintor aysenino Eusebio lbar en carta escrita en la década del cincuenta: "... Coyhaique es como una estrella que marca los cuatro puntos cardinales y por ella pasan y convergen todos los caminos de Aysén...". Luego, añade lo siguiente: "... Coyhaique es el centro de una estrella, cuyos vértices se dirigen a todos esos puntos que ofrecen perspectivas de inmenso porvenir..." (Santelices, 2002: 878). Con oportunidades y problemas, esta condición se ha mantenido hasta estos días.

\section{Los inicios del proceso de urbanización}

En la década de 1930 las grandes compañías ganaderas, que dieron origen a la estancia Coyhaique, comenzaron su retirada del territorio patagónico, proceso que también marcaría el fin de la colonización espontánea de los primeros colonos de la región de Aysén. A partir de este período, el Estado asumiría un rol fundamental en el poblamiento regional y en inversiones en obras públicas, 
comenzando activamente la entrega de títulos de dominio y la construcción de caminos de penetración desde Puerto Aysén, situación que favorecería el poblamiento de la ciudad de Coyhaique.

En el año 1948, y luego de 19 años de la fundación de la ciudad, Coyhaique comenzaba, lenta y sostenidamente, su despegue urbano, consolidando su posición primada dentro del territorio regional. En ese período la ciudad ya poseía una superficie de, aproximadamente, 146,9 hectáreas, aumentando su área urbana en 114,9 hectáreas respecto del año 1929 (Ministerio de Tierras y Colonización, 1948). El crecimiento se había desarrollado de manera continua a partir del centro histórico, lugar de localización de la plaza de armas y de los principales servicios públicos existentes a la fecha. Como dato ilustrativo, se puede señalar que, en promedio y considerando los 19 años transcurridos desde la etapa fundacional hasta el año 1948, la ciudad habría crecido a una tasa de seis hectáreas/año, principalmente sobre terrenos rurales y agrícolas que circundaban el área urbana. Desde un punto de vista espacial, la impronta de dichas parcelas o lotes rurales, sería asumida en el diseño urbano del casco antiguo de la ciudad, definiendo el número de manzanas posibles dentro de un lote $y$ el tamaño de los predios en su interior. Hoy en día, por lo menos en el centro histórico, dicho diseño urbanístico se ha mantenido, con superficies prediales que varían en un rango de 800 a $1.500 \mathrm{~m}^{2}$, con sitios tipo de 25 metros de frente por 50 metros de fondo (SEREMI MINVU, 2006).

En la década del setenta $y$, debido principalmente a la crisis de una de las principales actividades regionales, como lo es la ganadería, la actividad económica en Aysén pasa a depender, directa e indirectamente, de la acción del Estado y la inversión pública, adquiriendo los centros urbanos, y especialmente Coyhaique, un rol fundamental en el desarroIlo regional. Nuevas políticas de colonización en áreas aisladas, una fuerte movilidad de población y la construcción del tramo norte de la carretera Austral en los años ochenta, darían inicio a una nueva etapa en el proceso de urbanización, con efectos significativos sobre la ciudad de Coyhaique y las actividades turísticas.

\section{Coyhaique en la década de los ochenta}

En el año 1984 la ciudad de Coyhaique ya había ocupado gran parte de las parcelas o lotes rurales que la circundaban, especialmente hacia el este y entre el río Coyhaique, por el norte, y el cerro Divisadero, por el sur. La superficie urbana, estimada para ese período, había alcanzado a 468,2 hectáreas, con un incremento de 321,3 hectáreas respecto del año 1948. De este modo, la ciudad, en promedio y durante un lapso de 36 años, había crecido a una tasa de 8,9 hectáreas/año, valor equivalente, más o menos, a la superficie de una parcela o lote rural incorporado al desarrollo urbano en dicho período, según el plano de la ciudad de Coyhaique elaborado el año 1948 por el Ministerio de Tierras y Colonización, hoy Ministerio de Bienes Nacionales (Ministerio de Tierras y Colonización, 1948; Figura Nº 2).

Durante toda las décadas del ochenta y del noventa continuaría el sostenido y rápido proceso de urbanización en la región de Aysén, concentrándose cada vez más la población y actividades de servicio en las ciudades primadas de Coyhaique y Aysén. A su vez, las actividades agropecuarias y silvícolas, ya deprimidas en décadas pasadas, disminuirían sensiblemente su aporte al PIB regional, consolidándose y aumentando su participación relativa los sectores de pesca y acuicultura. Lo anterior, en un contexto de importantes esfuerzos de mejoramiento de la conectividad regional, expresada, principalmente, en la inversión pública en nuevos caminos de penetración que, descolgándose de la carretera Austral, permitieron vincular con la capital regional una serie de centros poblados localizados en la zona de fiordos y canales costeros de la región.

Desde el punto de vista de las migraciones, es importante destacar que el $43 \%$ de la población urbana de la comuna de Coyhaique nació en una comuna distinta a ella, mientras que respecto a las inmigraciones recientes, y de acuerdo a los resultados del Censo del año 2002, el $16 \%$ de la población que estaba viviendo en la comuna de Coyhaique el año 2002 (6.602 personas), lo hacía en otra comuna el año 1997; principalmente en otras comunas de la región de Aysén (3,9\%) y un porcentaje importante proveniente de la Región Metropolitana de Santiago (3,6\%). 


\section{Los nuevos patrones de urbanización}

A través de los años Coyhaique ha continuado su lento y sostenido proceso de crecimiento urbano, concentración de población, servicios y equipamientos a escala regional. Las áreas rurales que circundaban la ciudad, especialmente aquellas localizadas hacia los ríos Coyhaique, Simpson y el cerro Divisadero fueron incorporadas a la trama urbana bajo diferentes modalidades de uso, densidades de ocupación del suelo y grupos socioeconómicos. En los últimos 22 años, es decir, entre 1984 y el año 2006, serían incorporadas 193,5 hectáreas de nuevos suelos urbanos, básicamente por agregación de nuevas zonas residenciales a la trama urbana preexistente (Figura $\mathrm{N}^{\circ} 3$ ). De este modo, Coyhaique alcanzaría una superficie de 661,7 hectáreas, con un valor promedio, entre los años 19842006, de 8,8 hectáreas/año (Cuadro № 1).

El crecimiento observado, e irradiado desde el centro histórico, alcanzaría ambos ríos, con urbanizaciones pericentrales de viviendas sociales de alta densidad. El tejido urbano se diversifica y surgen unidades de paisaje urbano claramente identificables, sobre la base de elementos naturales que actúan, bien como factores condicionantes o limitantes del proceso de crecimiento, o bien como separadores y diferenciadores de grupos sociales. Junto con este proceso, también se produciría un aumento sostenido de la población de Coyhaique, duplicándose entre los años 1948 y 1984, y de su participación relativa respecto de la población total de la región de Aysén (Cuadro $N^{\circ} 1$ ).

Buen ejemplo de la segregación socioespacial en Coyhaique, ha sido el importante auge de proyectos inmobiliarios para grupos de altos ingresos, localizados, la mayoría de ellos, cerca de los ríos Coyhaique, Simpson, El Claro y el camino a Ñirihuao. Se trata de parcelas y loteos de entre 5.000 y $10.000 \mathrm{~m}^{2}$ que abarcan, de acuerdo a la información disponible y a la interpretación de imágenes satelitales, una superficie aproximada de

Figura $\mathrm{N}^{\circ} 2$

Trama urbana de Coyhaique año 1948 y división predial

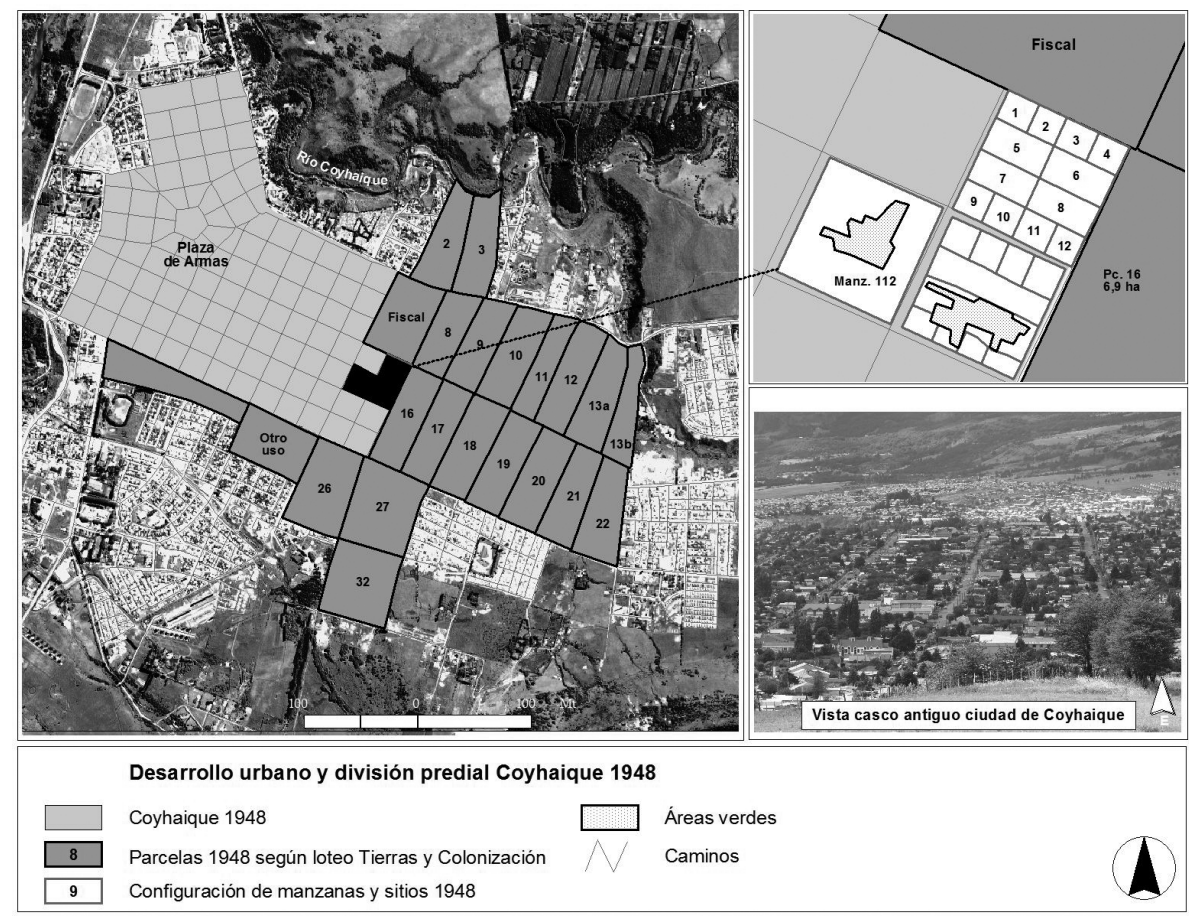

Fuente: Elaboración propia. 
313,4 hectáreas. Los de mayor importancia son las parcelas Río El Claro, hacia el suroeste, El Verdín, hacia el noreste de la ciudad, y los proyectos Hacienda Munilla y Loteo Los Sauces, hacia el sureste de Coyhaique.
Se trata de zonas urbanas más bien autónomas y escindidas de la trama histórica de la ciudad, herederas de la tradición rural que forma parte del acervo urbano de Coyhaique. Presentan una baja densidad en la

Figura $\mathrm{N}^{\circ} 3$

Evolución urbana de Coyhaique 1948-2008

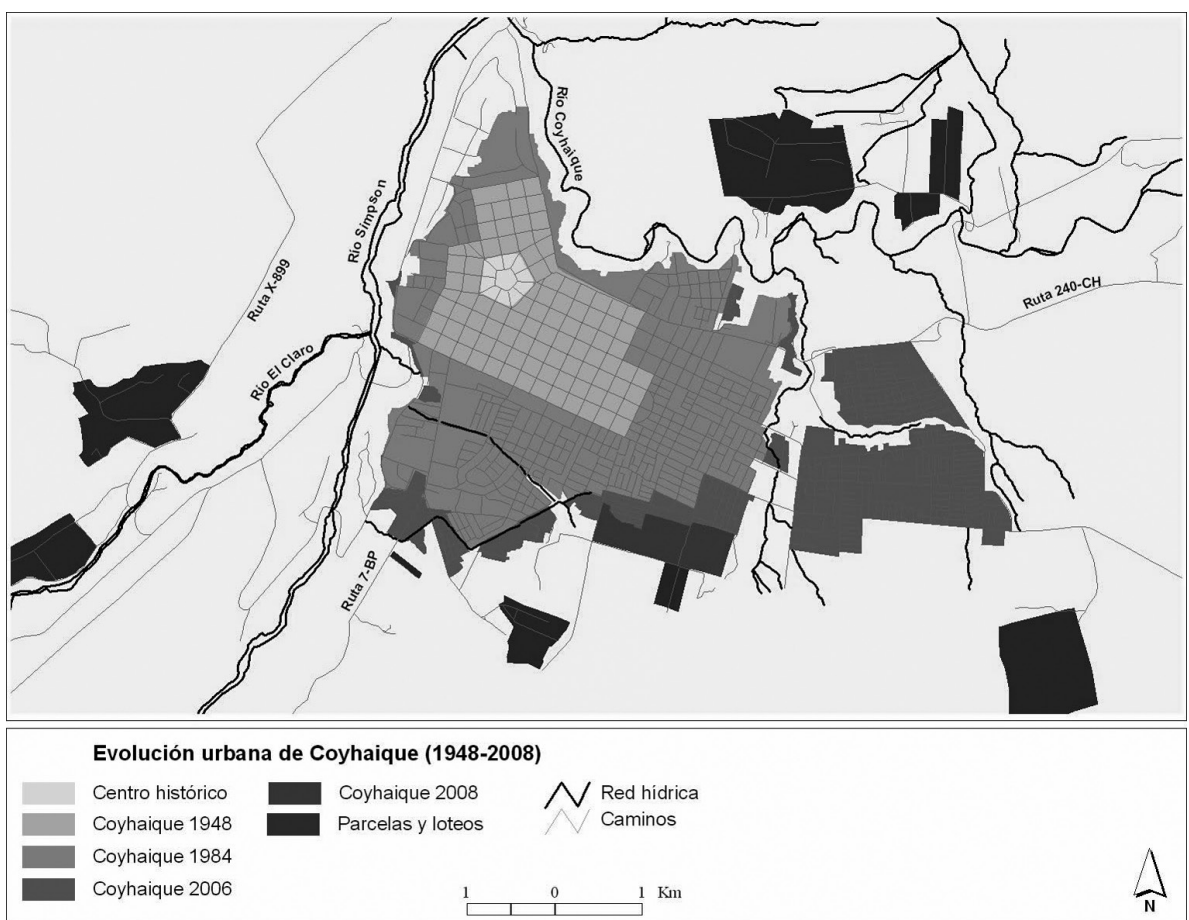

Fuente: Elaboración propia.

\section{Cuadro $\mathrm{N}^{\circ} 1$}

Evolución de la superficie urbana en la ciudad de Coyhaique (1929-2008)

\begin{tabular}{|c|c|c|c|c|c|c|c|}
\hline Año & $\begin{array}{c}\text { Superficie } \\
\text { urbana (ha) }\end{array}$ & $\begin{array}{c}\text { Período } \\
\text { (años) }\end{array}$ & $\begin{array}{c}\text { Incremento } \\
\text { neto (ha) }\end{array}$ & $\begin{array}{c}\text { Crecimiento } \\
\text { estimado (ha) }\end{array}$ & $\begin{array}{c}\text { Población } \\
\text { (miles/ha) }\end{array}$ & $\begin{array}{c}\text { Población regional } \\
\text { (miles/ha) }\end{array}$ & $\%$ \\
\hline 1929 & 32 & - & - & - & - & 9.715 & - \\
1948 & 146,8 & 19 & 114,9 & 6 & 8.000 & 26.262 & 30,5 \\
1984 & 468,2 & 36 & 321,3 & 8,9 & 29.163 & 66.361 & 43,9 \\
2002 & 581,9 & 18 & 113,7 & 6,3 & 44.987 & 91.492 & 49,2 \\
2006 & 661,7 & 4 & 79,8 & 19,9 & - & - & - \\
2008 & 686,2 & 2 & 24,5 & 12,3 & - & - \\
\hline
\end{tabular}

Fuente: Elaboración propia en base a interpretación de imágenes satelitales de los años 1984 y 2006, Plano Ministerio de Bienes Nacionales y Actualización del Plan Regulador Comunal de Coyhaique. 
ocupación del suelo y de población, junto con un buen asoleamiento de las laderas, una amplia cuenca visual sobre los ríos Coyhaique, Aysén y El Claro, una atractiva oferta de paisajes rurales y recursos hídricos, seguridad y exclusividad. Una nueva forma de crecimiento guiada por el mercado inmobiliario $y$, posiblemente, el estatus y preferencias de los consumidores. Al igual que otras ciudades del país, no existen muchas diferencias en estas formas de crecimiento que, de una u otra manera, consagran los desequilibrios y desigualdades propias de nuestra sociedad actual, cuya expresión espacial, urbana y social es claramente observable en la ciudad de Coyhaique.

No obstante lo anterior, el centro histórico aún mantiene su rol funcional y eminentemente prestador de servicios y equipamientos no solo de escala comunal, sino que también de escala regional. En esta parte de la ciudad, de antigua consolidación, se observan grandes construcciones en predios que varían entre los $800 \mathrm{~m}^{2}$ y $1.500 \mathrm{~m}^{2}$, resabios de las antiguas parcelas rurales de la etapa fundacional, y que presentan importantes espacios vacíos en su interior (SEREMI MINVU, 2006). A medida que la ciudad ha crecido, especialmente hacia el suroriente, el tamaño predial se reduce, con sitios inferiores a los $250 \mathrm{~m}^{2}$, principalmente en urbanizaciones sociales del SERVIU en áreas o sectores periféricos (SEREMI MINVU, 2006). Lo anterior, indudablemente, está relacionado con mayores densidades de ocupación del suelo urbano y un menor porcentaje de áreas libres en la configuración de las manzanas. Dentro de este esquema o fisonomía de desarrollo urbano, no solo los ríos Coyhaique y Simpson han actuado como elementos estructuradores o separadores de grandes zonas o macroáreas, sino también una serie de pequeñas quebradas y esteros que han delimitado barrios y proyectos urbanos para diferentes grupos socioeconómicos, especialmente hacia el suroriente.

Por otra parte, también es posible advertir una relación directa entre las áreas o barrios que presentan una mayor densidad en la ocupación del suelo urbano y menor tamaño predial, especialmente los proyectos de viviendas sociales impulsados por el SERVIU en los últimos años en la zona suroriente, y una menor calidad y materialidad de la construcción. Obviamente, la segregación socioespacial de la población está presente en la ciudad de Coyhaique, localizándose las familias de estratos bajos y medios, preferentemente, en aquellos sectores con mayores niveles de atomización predial. Tal como ocurre en otras ciudades del país, no existen muchas posibilidades o alternativas de localización para los grupos sociales de más bajo ingreso, habida consideración de la escasez de terrenos urbanizables, y a precios viables, susceptibles de ser adquiridos por el Estado.

Para graficar esta situación se tomaron como ejemplos dos tipologías de proyectos urbanos de la ciudad de Coyhaique, que responden a diferentes formas de crecimiento de la ciudad, densidades de ocupación del suelo, perfiles sociodemográficos de sus residentes, ofertas inmobiliarias públicas y privadas y entornos geográfico-paisajísticos bastantes diferenciados (Cuadro $\mathrm{N}^{\circ} 2$ ). El primero de ellos se localiza hacia el nororiente de la ciudad, próximo o adyacente a la ribera norte del río Coyhaique, y es conocido con el nombre de El Verdín (Figura $N^{\circ} 4$ ). La compra y posterior subdivisión de propiedades rurales dio origen a 80 lotes, con una superficie total, aproximada, de 54,4 hectáreas y un promedio de 0,7 hectáreas/lote. Si se considera como supuesto grupos familiares de 5 individuos y la ocupación de todas las propiedades, dicha zona podría albergar una población de 400 personas, con una densidad estimada de 1,5 vivienda/hectárea y 7,3 habitantes/hectárea. En contraposición, un proyecto SERVIU localizado hacia el suroriente de Coyhaique, en los faldeos del cerro Divisadero, presenta un total de 122 sitios $y / o$ viviendas sobre una superficie de 3,3 hectáreas y un promedio de 37 viv./ha. Si se aplican los mismos supuestos que en el caso anterior, la población total ascendería a 610 personas con una densidad de 184,8 hab./ha.

Los resultados indican que la ciudad de Coyhaique está creciendo, especialmente a partir de la década del noventa, a mayores distancias del casco histórico, dejando atrás, paulatinamente, una fase de extensión o crecimiento continuo que no superaba los 1.000 metros de distancia respecto de la trama urbana del año 1948, especialmente para destinos o usos residenciales. De esta 
manera, y hasta mediados de la década del ochenta, la agregación de suelos urbanizados sería continua, prolongándose la ciudad sobre gran parte de la meseta, a los pies del cerro Divisadero, y hacia las riberas de los ríos Coyhaique y Simpson. Las crecientes demandas de suelo urbano, especialmente en la década del noventa, tendrían un claro impacto en la forma tradicional de crecimiento observada en décadas pasadas. La ciudad se aleja cada vez más del casco fundacional y una nueva tipología comienza a predominar: un crecimiento no continuo, a mayores distancias de la trama urbana, con

Cuadro $\mathrm{N}^{\circ} 2$

Proyectos urbanos tipo en Coyhaique

\begin{tabular}{|l|c|c|c|c|c|c|}
\hline $\begin{array}{c}\text { Nombre } \\
\text { proyecto }\end{array}$ & Tipología & $\begin{array}{c}\text { Superficie } \\
\text { (ha) }\end{array}$ & $\begin{array}{c}\text { Número } \\
\text { lotes y/o } \\
\text { sitios }\end{array}$ & $\begin{array}{c}\text { Densidad } \\
\text { ocupación } \\
\text { suelo (viv./ha) }\end{array}$ & $\begin{array}{c}\text { Densidad } \\
\text { población } \\
\text { (hab./ha) }\end{array}$ & $\begin{array}{c}\text { Valor } \\
\text { estimado } \\
\text { (UF) }\end{array}$ \\
\hline El Verdín & $\begin{array}{c}\text { Parcelas de } \\
\text { agrado } \\
\text { Proyecto }\end{array}$ & 54,4 & 80 & 1,5 & 7,3 & $\begin{array}{c}625 \text { UF/ } \\
\text { ha }\end{array}$ \\
$\begin{array}{c}\text { Proyecto } \\
\text { SERVIU }\end{array}$ & $\begin{array}{c}\text { subsidiado estrato } \\
\text { social medio }\end{array}$ & 3,3 & 122 & 37 & 184,8 & $\begin{array}{c}1.000 \text { UF/ } \\
\text { viv. }\end{array}$ \\
\hline
\end{tabular}

Fuente: Elaboración propia en base a la interpretación de imágenes satelitales y verificación en terreno.

Figura $\mathrm{N}^{\circ} 4$

Parcelación EI Verdín y proyecto SERVIU Coyhaique

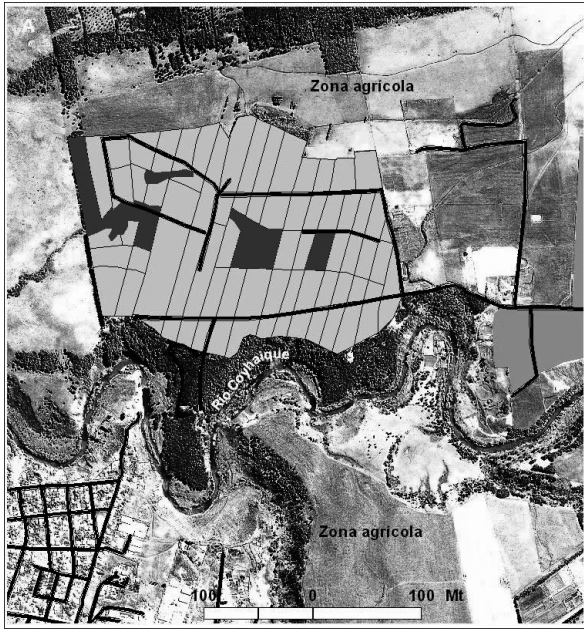

A Parcelación EI Verdín
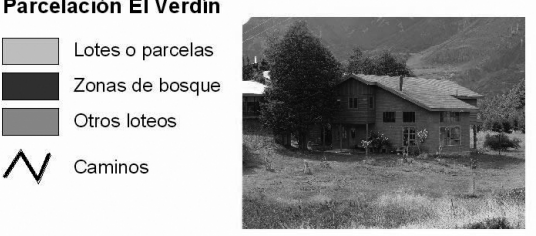

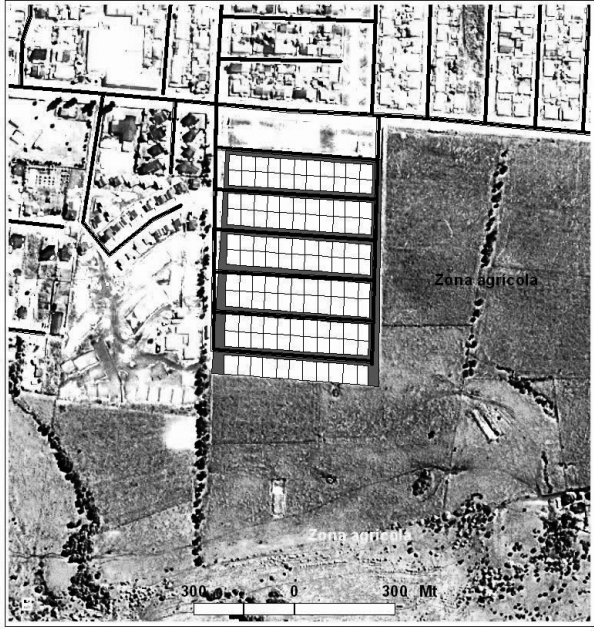

B Proyecto SERVIU

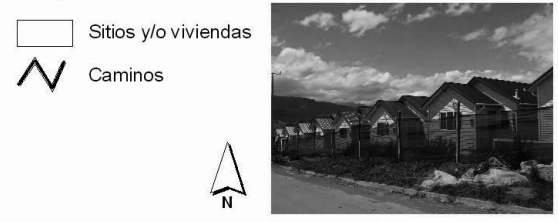

Fuente: Elaboración propia. 
proyectos residenciales separados o segregados del resto de la ciudad por elementos naturales que actúan como ejes estructuradores, especialmente los ríos Coyhaique y Simpson (Figura $\mathrm{N}^{\circ} 5$ ). Una breve síntesis de los datos indica que, aproximadamente, un $55,7 \%$ de la superficie urbana actual está asociada a una forma de crecimiento continua y un $44,3 \%$ a un crecimiento no continuo (Cuadro $\mathrm{N}^{\circ}$ 3). En este último caso, principalmente loteos, parcelas de agrado y condominios, algunos de los cuales se localizan a más de 5 kilómetros del centro de la ciudad de Coyhaique.

Desde la perspectiva de la competitividad por el acceso a suelos urbanos, con objetivos distintos al uso residencial, es posible afirmar que no existen, por el momento, conflictos entre actividades que pretendan similares localizaciones o bien ubicaciones que atenten contra la rentabilidad o plusva- lía de otras, como podría ser el caso del uso industrial, de almacenamiento y distribución de bienes agrícolas, pecuarios, forestales y pesqueros, respecto a destinos residenciales. En este sentido, las actividades industriales se ubican, preferentemente, en la periferia de la ciudad, hacia el suroeste y entre los ríos Simpson y El Claro, más bien alejadas del centro histórico, de zonas residenciales consolidadas y de loteos o parcelas de agrado, con una superficie total, estimada para el año 2008, de 59,8 hectáreas (Figura $N^{\circ} 6$ ). Finalmente, algunas de estas instalaciones industriales, especialmente aquellas localizadas en la periferia sureste, corresponden a grandes sitios ocupados por empresas constructoras como áreas de acopio de materiales de construcción, bodegaje y patio de maquinaria, situación que también explica el auge de las actividades de construcción observada en las últimas décadas en la ciudad de Coyhaique.

Figura $\mathrm{N}^{\circ} 5$

Crecimiento urbano y distancias al centro histórico de Coyhaique

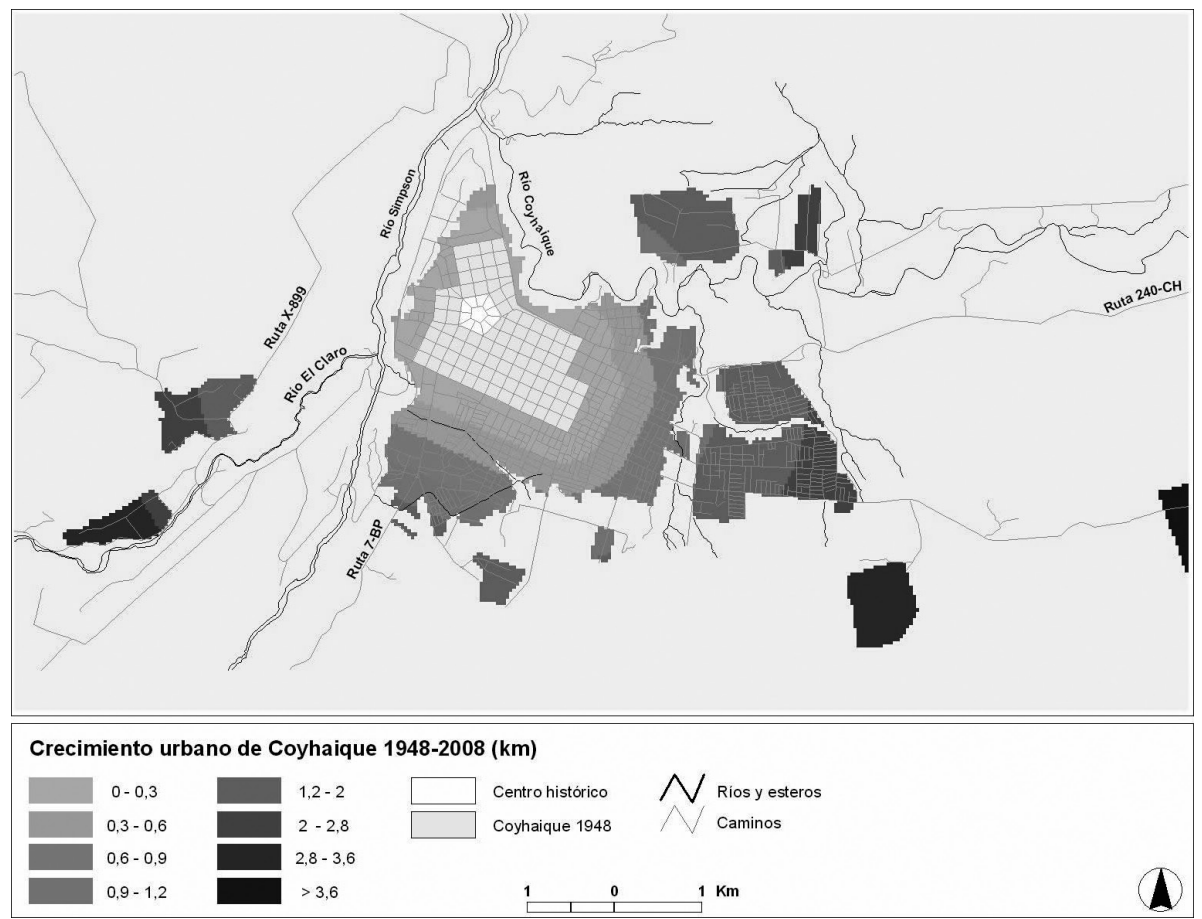

Fuente: Elaboración propia. 
Cuadro $\mathrm{N}^{\circ} 3$

Patrones de crecimiento ciudad de Coyhaique

\begin{tabular}{|c|c|c|c|c|}
\hline $\begin{array}{c}\text { Distancia crecimiento } \\
\text { observado año 1948 }(\mathrm{km})\end{array}$ & $\begin{array}{c}\text { Número } \\
\text { píxeles }\end{array}$ & $\begin{array}{c}\text { Superficie } \\
\text { estimada (ha) }\end{array}$ & $\begin{array}{c}\text { Superficie } \\
\text { acumulada (ha) }\end{array}$ & $\%$ \\
\hline $0-0,3$ & 3.206 & 288,5 & $2.885,0$ & 29,6 \\
$0,3-0,6$ & 1.232 & 110,9 & 399,4 & 11,4 \\
$0,6-0,9$ & 972 & 87,5 & 486,9 & 9 \\
$0,9-1,2$ & 612 & 55,1 & 542 & 5,7 \\
$1,2-2$ & 2.027 & 182,4 & 724,4 & 18,7 \\
$2-2,8$ & 792 & 71,3 & 795,7 & 7,3 \\
$2,8-3,6$ & 656 & 59 & 854,7 & 6,1 \\
$>3,6$ & 1.313 & 118,2 & 972,9 & 12,2 \\
Total & 10.810 & 972,9 & 972,91 & 100 \\
\hline
\end{tabular}

${ }^{1}$ Este valor incluye las superficies de loteos y parcelas de agrado.

Fuente: Elaboración propia en base a imágenes satelitales y cálculos realizados en ArcView.

\section{Las proyecciones de crecimiento}

Durante los últimos años Coyhaique ha continuado su proceso de crecimiento, especialmente hacia el sector suroriente de la ciudad, incorporando a la trama urbana, entre los años 2006 y 2008, un total de 24,5 hectáreas. Se trata, principalmente, de conjuntos residenciales para grupos sociales bajos y medios, subsidiados y financiados por SERVIU. Según estimaciones contenidas en la Actualización del Plan Regulador Comunal de Coyhaique, el incremento de suelo urbano, proyectado para el año 2012, sería bastante moderado, aumentando la superficie actual de la ciudad en un 43\% (SEREMI MINVU, 2006; INFRACON, 2004). En dicho análisis se proyecta, para un período de 20 años, una ciudad que alcanzaría una superficie urbana de 832 hectáreas, es decir, serían incorporadas 145,8 hectáreas de nuevos suelos urbanos respecto al año 2008, principalmente para usos o destinos residenciales.

Los supuestos de estas estimaciones, bastante realistas de acuerdo a la evolución histórica de la ciudad, se basan en cálculos de requerimientos de viviendas, de acuerdo a las proyecciones de población, la variación del PIB para cada actividad económica relevante y el comportamiento del empleo a ni- vel regional (SEREMI MINVU, 2006). De esta forma, y suponiendo una relación más bien lineal entre estas variables y el rol jerárquico y concentrador de la ciudad de Coyhaique, el consumo de suelo urbano, principalmente para usos habitacionales, equipamientos, áreas verdes, comercio e infraestructura vial, se proyecta para diferentes grupos socioeconómicos. De este modo, las estimaciones realizadas en el estudio de Actualización del Plan Regulador Comunal de Coyhaique, teniendo como base el año 2002 y una superficie urbana de 581,9 hectáreas, arrojaban una demanda de suelo, para el año 2010, de 81,5 hectáreas y de 230 hectáreas para el año 2020. Lo anterior, con un incremento neto de población de 20.500 personas y de 5.395 nuevas viviendas, incluido el déficit habitacional social que ascendería a 1.742 viviendas para, principalmente, grupos sociales de bajos ingresos (SEREMI MINVU, 2006).

Si bien estos datos se ajustan a la realidad urbana de la ciudad de Coyhaique, observada principalmente entre los años 2002, 2006 y 2008, especialmente para los nuevos requerimientos de suelo para usos residenciales de estratos socioeconómicos bajos y medios, no reflejan en toda su magnitud la dinámica y demandas específicas de los grupos de más altos ingresos. En particular, las enormes 
extensiones de terrenos rurales que, en los últimos años, se han transformado en parcelas de agrado, contribuyendo a una cada vez mayor fragmentación y diferenciación social de la ciudad. En otras palabras, ya no es posible hablar de la ciudad de Coyhaique solo a partir del área o núcleo central del sitio fundacional y su posterior crecimiento, sino que también de estos nuevos ensambles urbanos, cada vez más alejados del centro histórico y localizados en bellos y exclusivos entornos paisajísticos. Como dato ilustrativo se puede señalar que la superficie actual comprometida en estos loteos y parcelas rurales, que ascendía el año 2008, aproximadamente, a 313,4 hectáreas, representa, en la actualidad, el 45,6\% de la superficie urbana total de Coyhaique.

Como se puede apreciar, y tal cual lo establecen los instrumentos de planificación urbana que intentan regir los destinos de Coyhaique, particularmente el Plan Regional de Desarrollo Urbano y la Actualización del Plan Regulador Comunal, la ciudad continuará su proceso de crecimiento, con un incremento neto estimado de 10,2 hectáreas/año, cifra bastante más conservadora a las 19,9 hectáreas/año y 12,3 hectáreas/ año observadas entre los años 2002-2006 y 2006-2008, respectivamente. Al parecer la ciudad de Coyhaique ya habría alcanzado su peak de crecimiento y consumo de suelo urbano, especialmente entre los años 2002 y 2006, siendo esperable, como algunas cifras ya lo indican, un mayor auge de la ciudad de Aysén y otros centros menores, como Puerto Cisnes y Cochrane. Indudablemente, la dinámica de la actividad económica regional, en términos de importantes inversiones proyectadas y nuevas fuentes de empleo, asociadas a actividades emergentes como el turismo y otras posiblemente vinculadas al sector energético e industrial, puede inducir o revertir, en parte, el proceso altamente concentrador que ha caracterizado, a través de su reciente historia urbana, a la ciudad de Coyhaique.

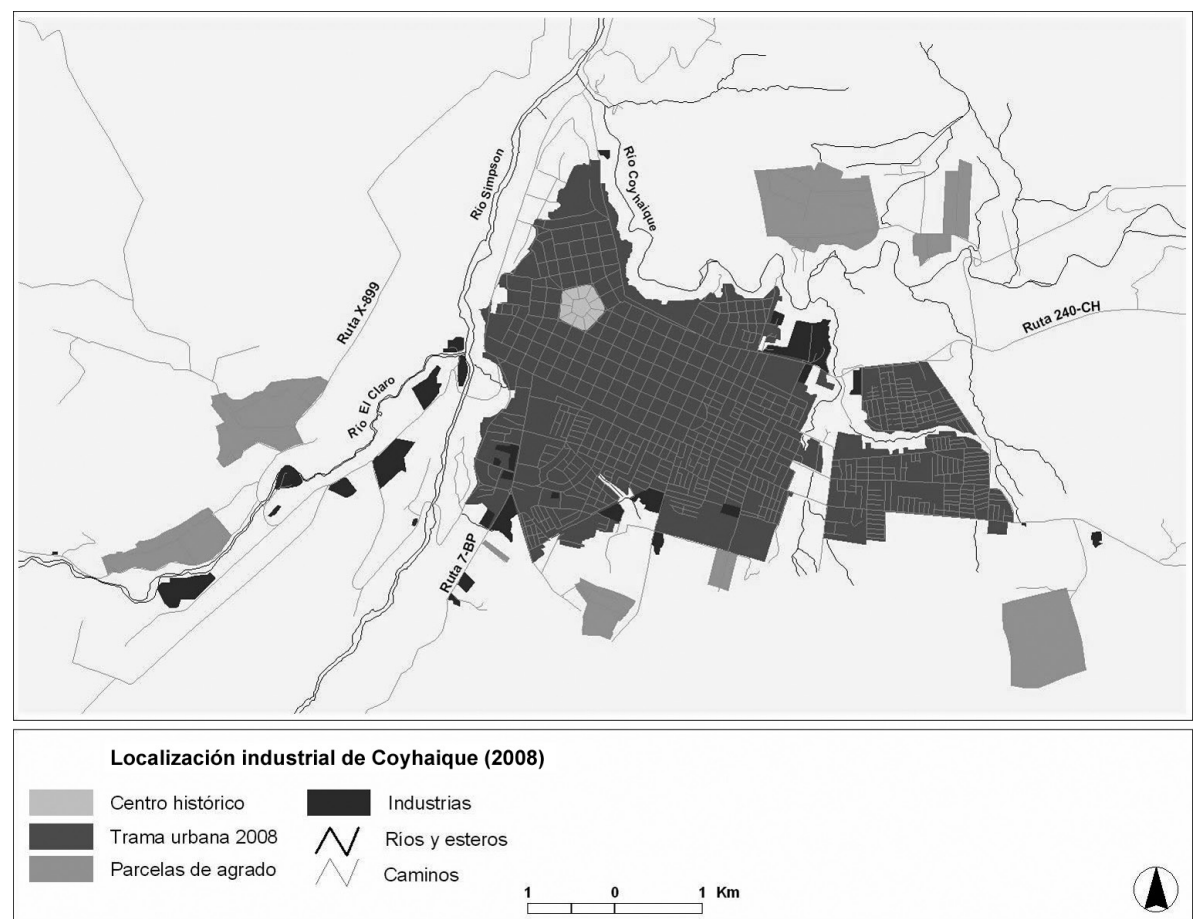

Fuente: Elaboración propia. 
En esta perspectiva, el mejoramiento sostenido de la conectividad, expresada en más y mejores caminos de penetración a localidades aisladas, permitiría, en un contexto de planificación estratégica, un desarrollo más equilibrado de los centros poblados de la región evitando, a la vez, el éxodo rural hacia la capital y otros centros urbanos intermedios. En definitiva, el crecimiento de Coyhaique no puede sostenerse de manera continua a través del tiempo, pese a la relativa juventud de esta hermosa ciudad. Inevitablemente, surgirán mecanismos de control que, vinculados a factores de tipo económico, demográficos, disponibilidad de suelos urbanizables, costos de urbanización, riesgos naturales, áreas protegidas, preferencias y poder adquisitivo de los consumidores, pondrán en jaque o bien moderarán el proceso de crecimiento, inclusive bajo el mandato legal y directrices de los instrumentos de planificación urbana actualmente vigentes.

\section{Consideraciones finales}

Los resultados obtenidos en Coyhaique, en la primera fase de este proyecto de investigación en ciudades australes de Chile, han conducido a través de una crónica urbana que, en una primera lectura, arroja ciertas semejanzas o similitudes con el desarrollo y evolución más reciente de otras ciudades de Chile, como es el caso de aquellos centros intermedios localizados en la zona centro sur o central del país. Una rápida urbanización, producto de ventajas originarias o fundacionales de localización vinculadas con la posición geográfica de las ciudades respecto a vías de comunicación y transporte, esfuerzos significativos del Estado por consolidar la ocupación y explotación de territorios geográficamente fragmentados y aislados, importantes movimientos migratorios desde regiones norteñas hacia el sur austral, promisorio y patagónico, junto con una migración intrarregional desde los centros poblados menores a la ciudad principal, han sido algunos de los factores que han movilizado y orientado el rápido desarrollo urbano de la ciudad de Coyhaique.

A partir de un núcleo fundacional homogéneo, que se fundía con la ruralidad y costumbres patagónicas, lenta, pero sostenida- mente, la ciudad y la región de Aysén, daría inicio a un rápido proceso de urbanización y concentración, cada vez mayor, de población, servicios y equipamientos. Pese a los ingentes esfuerzos del Estado chileno, medidos a través de políticas, planes o programas de colonización, inversiones públicas directas o indirectas en materia de infraestructura y desarrollo agropecuario, la ruralidad regional perdería vitalidad y alternativas económicas, frente a una creciente consolidación de lo urbano, cuya máxima expresión regional es la ciudad de Coyhaique. Esto, que no es nuevo en el desarrollo histórico del campo y la ciudad en Chile, como también en otros países latinoamericanos, comenzaría a operar como factor de desequilibrio en los procesos de poblamiento regional y la dinámica de los centros urbanos. Más allá de la espontaneidad y velocidad del proceso de crecimiento, que daría origen a nuevas formas, patrones y artefactos de urbanización, Coyhaique comienza un proceso de adaptación a los nuevos tiempos que, entre otras cosas, se reflejaría no solo en la evolución y configuración de su trama urbana, sino también en la diferenciación socioespacial de la población que dicha evolución provocaría.

En otras palabras, nuevos contingentes de población, provenientes de la misma comuna de Coyhaique, de la región de Aysén, de otras regiones del país y, también, de la vecina región patagónica de Argentina, presionarían, cada vez más, por una alternativa de localización dentro de la ciudad. Nuevos requerimientos y demandas surgirían, proyectándose un crecimiento en extensión, continuo o no continuo y planificado o no planificado, más allá de las condicionantes físicas o naturales del sitio de emplazamiento fundacional. En la actualidad, dichos elementos naturales, principalmente los ríos Coyhaique, Simpson y las pequeñas quebradas que disectan la planicie o meseta sobre la cual se emplaza la ciudad, han contribuido a diferenciar y/o segregar en diferentes macrozonas la ciudad y, en algunos casos, se han transformado en áreas de riesgo para la localización de usos y/o actividades, principalmente los destinos residenciales.

Desde una perspectiva algo más sociológica, y a modo de hipótesis para futuras investigaciones, sería posible observar una 
estrecha relación entre la configuración de la trama urbana, a partir del centro histórico o casco fundacional, y la diferenciación social y cultural de sus habitantes. Antecedentes preliminares, como la configuración de las manzanas del casco antiguo y los mayores tamaños prediales observados en los sectores más céntricos, remiten a una fase de la evolución urbana de Coyhaique con una marcada impronta rural que, entre otros aspectos, se refleja en una baja densidad de ocupación del suelo y la existencia de grandes patios interiores con pequeños sectores de cultivos. En otras palabras, una ciudad más compacta y uniforme, más plenamente integrada y dependiente del entorno rural que la circundaba. Posiblemente, este sector de la ciudad hace evocar a sus primeros habitantes-colonizadores, siendo posible observar, hasta el día de hoy, su legado cultural y arquitectónico.

A medida que la ciudad crece no solo la trama urbana se torna más compleja y fragmentada, sino también la composición y origen sociocultural de sus residentes. Trabajadores urbanos y obreros campesinos, pescadores chilotes, ganaderos patagónicos, profesionales y técnicos, funcionarios públicos y militares, van demandando, paulatinamente, sus derechos sobre una ciudad que, por lo menos en las últimas décadas, muestra evidentes síntomas de agotamiento y cansancio. Ya no es posible, o por lo menos con muchas restricciones, una localización residencial para los grupos de menores ingresos que asegure condiciones mínimas de habitabilidad e integración social. Nuevos proyectos residenciales, conducidos por el mercado inmobiliario y el estatus asociado a las nuevas generaciones de consumidores de suelo urbano-rural, van conformando, cada vez más, una ciudad de difícil lectura e interpretación, segregada y, posiblemente, carente de aquellos atributos urbanísticos y culturales que marcaron sus primeras etapas de desarrollo y que la diferenciaron de las ciudades del centro-sur de Chile más vinculadas con el proceso fundacional español, inclusive desde el punto de vista morfológico.

Desde esta perspectiva, se puede señalar que el proceso de desarrollo urbano de Coyhaique ha carecido, especialmente en las últimas décadas, de criterios de equidad y eficiencia en la asignación y distribución del suelo urbano, configurándose, de este modo, una ciudad social y físicamente fragmentada que repite, como en otras ciudades más grandes de nuestro país, los mismos errores, vacíos y omisiones tan propias de los procesos de planificación urbana y territorial nacionales.

\section{Referencias bibliográficas}

ABLER, R.; ADAMS, J. \& GOULD, P. Spatial Organization: The geographers view of the world. Englewood Cliffs: N. J., PrenticeHall, 1971.

AGUAYO, M.; WIEGAND, T.; AZÓCAR, G.; WIEGAND, K. \& VEGA, C. Revealing driving forces of mid-cities urban growth patterns using spatial modeling: a case study of Los Angeles (Chile). Ecology and Society, 2007, vol. 12, № 1. Disponible en Internet: http://www.ecologyandsociety.org/vol12/iss1/ art13/

AZÓCAR, G.; SANHUEZA, R. y HENRÍQUEZ, C. Análisis del cambio en los patrones de crecimiento urbano en una ciudad intermedia de Chile central: un caso de estudio en Chillán. EURE, 2003, vol. 29, № 87, p. 79-92.

AZÓCAR, G.; ROMERO, H.; SANHUEZA, R.; VEGA, C.; AGUAYO, M. \& MUÑOZ, M. Urbanization patterns in chilean mid-sized cities and their impacts on the social restructuring of urban space: a case study in Santa Maria de Los Angeles, Central Chile. Land Use Policy, 2007, vol. 24, No 1, p. 199-211.

AZÓCAR, G.; HENRÍQUEZ, C.; VALENZUELA, C. y ROMERO, H. Tendencias sociodemográficas y segregación socioespacial en Los Ángeles, Chile. Revista de Geografía Norte Grande, 2008, № 41, p. 103-128.

BELLET, C. y BELTRÃO, M. E. (eds.). Las ciudades medias o intermedias en un mundo globalizado - As cidades médias ou intermédiárias em num mundo globalizado. Lleida: Edicions de la Universitat de Lleida, 2009.

BELTRÃO, M. E. (ed.) Cidades médias: espaços em transição. São Paulo: Editora Expressão Popular, 2007. 
BORSDORF, A. El desarrollo urbano de Valdivia. Estudio de caso de una ciudad mediana. Espacio y Desarrollo, 2000, № 12, p. 45-82.

BORSDORF, A. Cómo modelar el desarroIlo y la dinámica de la ciudad latinoamericana. EURE, 2003, vol. 29, No 86, p. 37-49.

CELADE. División de Población de la Comisión Económica para América Latina y el Caribe (CEPAL) de las Naciones Unidas. Santiago: CEPAL, 2001. Disponible en Internet: www.eclac.cl $\backslash$ celade $\backslash$ Redatam

CLAWSON, M. Urban sprawl and speculation in suburban land. Land Economic, 1962, No 38, p. 99-113.

GOODALL, B. The economic of urban areas. Oxford: Pergamon Press, 1972.

HenríQueZ, C. y AZÓCAR, G. Patrones de crecimiento en ciudades intermedias chilenas y su impacto en la sustentabilidad urbana. En: BELTRÃO, M. E. (org.), Cidades médias: espaços em transição. São Paulo: Editora Expressão Popular, 2007, p. 283312.

HENRÍQUEZ, C.; AZÓCAR, G. \& ROMERO, H. Monitoring and modeling the urban growth of two mid-sized Chilean cities. Habitat International, 2006, vol. 4, № 30, p. 945-964.

HERBERT, D. \& THOMAS, C. Urban Geography. A first approach. Nueva York: J. Wiley, 1982.

HIDALGO, R.; SALAZAR, A.; LAZCANO, R. y ROA, F. Periurbanización y condominios en el Área Metropolitana de Santiago de Chile. El caso de Pirque y Calera de Tango. Revista Geográfica Terra Australis, 2003, № 48, p. 117-138.

HIDALGO, R. y ARENAS, F. Del país urbano al país metropolitano. Transformaciones recientes en las ciudades chilenas. En: HIDALGO, R.; DE MATTOS, C. y ARENAS, F. (eds.). Chile: del país urbano al país metropolitano. Santiago: Instituto de Geografía, Pontificia Universidad Católica de Chile, Serie GEOlibros 12, 2009, p. 9-29.
INSTITUTO NACIONAL DE ESTADÍSTICAS (INE). Resultados Generales. Censo de Población y Vivienda, 1992. Santiago: INE, 1992.

INSTITUTO NACIONAL DE ESTADÍSTICAS (INE). XVII Censo de Población y VI de Vivienda. Síntesis de resultados, 2002. Santiago: INE, 2002.

INFRACON S. A. Diagnóstico Plan Regulador Intercomunal Coyhaique-Puerto Aysén, XI Región. Coyhaique: INFRACON S. A., 2004.

MARTINIC, M. De la Trapananda al Aysén. Una mirada reflexiva sobre el acontecer de la Región de Aysén desde la Prehistoria hasta nuestros días. Santiago: Biblioteca del Bicentenario, Pehuén Editores, 2005.

MINISTERIO DE TIERRAS Y COLONIZACIÓN. Población Coyhaique y Quintas. Plano original de subdivisión, Decreto N 1497. Coyhaique: Departamento de Mensura, 1948.

POMAR, J. La concesión del Aysén y el valle del Simpson: (notas y recuerdos de un viaje de inspección en Mayo y Junio de 1920). Santiago: Imprenta Cervantes, 1923.

RODRÍGUEZ, J. y VILLA, M. Distribución espacial de la población, urbanización y ciudades intermedias: hechos en su contexto. En: JORDÁN, R. y SIMIONI, D. (comp.). Ciudades intermedias en América Latina y el Caribe. Santiago: Comisión Económica para América Latina y el Caribe; Ministero degli Affari Esteri Cooperazione Italiana, 1998, p. 25-68.

ROMERO, H. y TOLEDO, X. Crecimiento económico y desigualdades regionales en Chile; indicadores de evaluación ambiental estratégica. Anales de la Sociedad Chilena de Ciencias Geográficas, 1998, p. 537-570.

ROMERO, H.; HENRÍQUEZ, C.; AZÓCAR, G.; VÁSQUEZ, A.; SOUZA, N.; RIVEROS y MORÁN, A. Sistemas de Información Geográfica para el desarrollo sustentable de las ciudades chilenas. En: Concepción, Segundo Congreso Internacional Ciudad y Territorio Virtual, 2005, p. 52-58. Disponible en Internet: http://www.facd.ubiobio.cl/2ctv/ espanol.htm 
ROMERO, H.; VÁSQUEZ, A. y SMITH, P. Análisis crítico de las potencialidades y limitaciones para el desarrollo regional de Aysén. Investigaciones Geográficas Chile, 2008, Nº 40, p. 67-98.

ROVIRA, A. Puerto Montt: el paso de una ciudad menor a centro de desarrollo interregional en una ciudad del sur de Chile. Espacio y Desarrollo, 2000, № 12, p. 83-102.

SABATINI, F. Direcciones para el futuro. En: JORDÁN, R. y SIMIONI, D. (comp.). Ciudades intermedias en América Latina y el Caribe. Santiago: Comisión Económica para América Latina y el Caribe; Ministero degli Affari Esteri Cooperazione Italiana, 1998, p. 127-214.

SABATINI, F. Reforma de los mercados de suelo en Santiago de Chile: efectos sobre los precios de la tierra y la segregación residencial. EURE, 2000, vol. 26, No 77, p. 49-80.

SANTELICES, L. Aysén, un proyecto exitoso de descentralización, memoria históricaadministrativa 1964-1970. Tomo II. Santiago: Edit. Orígenes, 2002.
SANTOS, M. La naturaleza del espacio. Técnica y tiempo. Razón y emoción. Madrid: Ariel Geografía, 2000.

SEGURA, D. El sentido del bienestar en una política social de vivienda: el caso de la fase piloto del Chile Barrio. Scripta Nova, 2003, vol. 7, № 146. Disponible em Internet: http://www.ub.es/geocrit/sn/sn-146(089).htm

SECRETARÍA REGIONAL DE PLANIFICACIÓN Y COORDINACIÓN (SERPLAC). Plan Regional de Ordenamiento Territorial Región de Aysén, 2005. Coyhaique: SERPLAC, 2005.

SECRETARÍA REGIONAL MINISTERIAL DE VIVIENDA Y URBANISMO REGIÓN DE AYSÉN (SEREMI MINVU). Actualización Plan Regulador Comunal de Coyhaique. Coyhaique: MINVU, 2006.

VERA, V. Evolución de los paisajes de la Patagonia norte a través de los cambios del uso del suelo entre 1979-2007: cuenca inferior del río Simpson, Aysén. Tesis licenciado en educación. Concepción: Pedagogía en Historia y Geografía, Facultad de Educación, Universidad de Concepción, Chile, 2008. 